\title{
ESTUDO DE ALTERNATIVAS PARA O APROVEITAMENTO DE RESÍDUOS SÓLIDOS DA INDUSTRIALIZAÇÃO DO COCO
}

\author{
Graciana O. Silva ${ }^{1}$ e Carlos Enrique Jerônimo ${ }^{1}$ \\ ${ }^{1}$ Curso de MBA em Gestão e Perícia Ambiental, UNI-RN, CEP: 59.014-540, Natal-RN, Brasil. \\ E-mails: graciana-oliver@hotmail.com - c enrique@hotmail.com
}

http://dx.doi.org/10.5902/223613086935

\section{RESUMO}

A cultura do coqueiro vem se expandindo nos últimos anos, em função da demanda crescente do setor de água de coco verde. Devido a este acontecimento, observa-se a geração significativa de resíduos provenientes da sua produção. Dentro deste contexto, objetivou-se analisar as estratégias para o aproveitamento de resíduos de cascas de coco, através do aproveitamento da fibra de coco visando à redução de impactos ambientais e a verificação do tipo e do nível de benefícios econômicos e sociais através da tecnologia apresentando as potenciais formas de reciclagem a serem empregados através das cascas de coco propostos usos das fibras de coco com o objetivo de mitigar os impactos provocados pelas cascas, possibilitando a produção de novos produtos. A avaliação do potencial de aproveitamento do resíduo do coco pode ser uma alternativa para diminuir o espaço ocupado por estes resíduos em aterros sanitários e lixões. A metodologia trata de um estudo bibliográfico com abordagem qualitativa de cunho descritivo exploratório e levantamento de dados em agroindustriais e principais áreas de geração de resíduos do coco. Os resultados obtidos descrevem as diferentes técnicas descritas para o aproveitamento do potencial desses resíduos, em diferentes formas. Entretanto, mesmo as cascas de coco verdes sendo considerados como restos da agricultura com elevado potencial de reuso, contudo, infelizmente, foram encontradas raras ações praticadas no Brasil para o aproveitamento dessa potencialidade.

PALAVRAS-CHAVE: cascas de coco, fibra de coco e aproveitamento.

\section{ABSTRACT}

STUDY ALTERNATIVES FOR THE ENJOYMENT OF SOLID WASTE INDUSTRIALIZATION COCONUT

The coconut has been expanding in recent years, due to growing demand in the sector of green coconut water. Due to this event, there is a significant generation of waste from its production. Within this context, the objective was to analyze the strategies for the use of waste coconut husks, through the use of coconut fiber in order to reduce environmental impacts and check the type and level of economic and social benefits through technology presenting potential forms of recycling to be employed through the coconut shells proposed uses of coconut fibers in order to mitigate the impacts caused by shells, enabling the production of new products. The evaluation of the potential of using waste coconut can be an alternative to reduce the space occupied by these wastes in landfills and dumps. The methodology is a bibliographical study with qualitative approach of exploratory and descriptive data collection in key areas of agribusiness and waste generation from coconut. The results describe the various techniques described for the potential use of such wastes in different ways. However, even the green coconut husks being considered as 
remnants of agriculture with high potential for reuse, however, unfortunately, were found rare actions taken in Brazil to take advantage of this capability.

KEY-WORDS: coconut shells, fiber coconut and development.

\section{INTRODUÇÃO}

O coqueiro é originado do sudeste asiático, sendo cultivado em mais de 85 países, ocupando uma área de 14 milhões de hectares. No Brasil o coqueiro foi introduzido pelos portugueses em 1553, proveniente de Cabo Verde, com entrada pelo Estado da Bahia e posterior dispersão por todo litoral nordestino e daí para todo o Brasil. O coqueiro é considerado a árvore da vida, visto que dele se obtém mais de 100 produtos e subprodutos, destacando-se dentre esses a água de coco, coco ralado e o leite de coco. O coqueiro (Coccus nucifera L.) é uma planta de grande importância socioeconômica, que além de produzir a água de coco, o albúmen sólido para indústria de alimentos e de óleos, gera ainda uma grande quantidade de subprodutos e resíduos. No Brasil, com uma área plantada de 290.515 hectares são produzidos anualmente cerca de 2,29 bilhões de cascas, 469,76 milhões de folhas que caem naturalmente da planta e 469,76 milhões de cachos com ramos florais e brácteas, o que corresponde 3,84 milhões de tonelada de resíduos, sendo 1,53 milhões de casca e 1,69 milhões de folhas (Embrapa, 2010).

O fruto do coqueiro é constituído por albúmen líquido (água de coco), albúmen sólido ou amêndoa, endocarpo conhecido popularmente como "Quenga" e casca. A casca representa em torno de $57 \%$ do fruto sendo composta pelo mesocarpo (fibra e pó) e epicarpo (camada mais externa da casca). O volume e o peso da casca variam com as condições e da forma climáticas da região de plantio, a adubação, os tratos culturais e fitossanitários do coqueiro e a variedade cultivada (Embrapa, 2010).

Nos últimos anos, especial atenção vem sendo dada para minimização ou reaproveitamento de resíduos gerados nos diferentes processos industriais. As informações sobre a produção de lixo no Brasil, divulgadas pelos órgãos oficiais dão conta que o país produz cerca de 100 mil toneladas de lixo por dia, mas recicla menos de cinco por cento do lixo urbano, contra $40 \%$ reciclados nos Estados Unidos e na Europa. De tudo que é jogado todo dia no lixo, cerca de $35 \%$ poderiam ser reciclados ou reutilizados e outros 35\%, serem transformados em adubo orgânico (Silva et.al., 2003).

Atualmente, a maioria das cascas de coco, folhas e cachos do coqueiro são queimados ou descartados como lixo nas propriedades rurais produtoras de coco, nas ruas das grandes cidades e em lixões. Quando queimados produzem substâncias poluidoras do meio ambiente, quando descartados constituem meio adequado para procriação de animais peçonhentos e insetos vetores de doenças, servindo como agente poluidor do meio ambiente e de risco para a saúde da população.

Além disso, estão sendo eliminadas matérias-primas, infinitas e renováveis, de alto valor para a agricultura, sem as desvantagens ecológicas apresentadas por outros produtos como a turfa e a vermiculita, amplamente utilizadas, ao longo do tempo, como substratos, cuja extração gera graves problemas ambientais. 
Esses resíduos do coqueiro constituem também excelentes matérias primas para produção de substratos e adubos orgânicos de grande importância agronômica, social e econômica sem desvantagens ecológicas, podendo contribuir, de maneira significativa, para o aumento da produção e melhoria da qualidade dos alimentos. Esse fato se deve aos efeitos benéficos do adubo orgânico na recuperação e manutenção das características físicas e biológicas do solo, como conseqüência do aumento na retenção de água, porosidade, pH do solo e da infiltração de água, redução de temperatura, melhoria da estruturação do solo com a formação de grumos, diminuição da compactação, aumento da penetração das raízes e redução dos danos causados pela enxurrada.Esses efeitos são de extrema importância na redução dos efeitos da seca, economia da água de irrigação e a melhoria das condições ambientais para os microrganismos benéficos que vivem associados às raízes das plantas (Rhizobium e Micorriza).Tais atributos, caracterizam aspectos fundamentais da produção de alimentos.

As cascas, na forma de "briquetes" ou "blocos prensados" podem ser aproveitadas como carvão vegetal em substituição ao carvão de madeira, com grandes vantagens ecológicas e rendendo um valor calórico entre 3.000 e $4.000 \mathrm{kCal} / \mathrm{kg}$ (Embrapa, 2010).

O uso de fibras de coco como reforço em matrizes poliméricas é recente, porém apresenta vantagens em relação a outras fibras vegetais. A utilização de fibra vegetal, em particular fibra de coco, como reforço em compósitos com plásticos, apresenta várias vantagens quando comparada a outros materiais sintéticos, como, altas propriedades mecânicas específicas, biodegradabilidade, reciclabilidade, baixa densidade, não-abrasividade, baixo consumo de energia, baixo custo e oferta de empregos rurais (Santiago et al., 2005).

As fibras vegetais são formadas por diversos componentes químicos constituídos a base de Hidrogênio $(H)$ e Carbono (C), sendo os principais a celulose, a hemicelulose e a lignina (Silva, 2003). A celulose é um polissacarídeo formado por resíduos de D-glicopiranoses que formam longas cadeias lineares com alto grau de polimerização (formação de polímeros), se constitui na principal componente de todas as fibras vegetais, pois confere a mesma resistência mecânica (Silva, 2003; Passos, 2005).

A hemicelulose é constituída por uma mistura de polissacarídeos amorfos com grau de polimerização de 10 a 100 vezes menor que o da celulose. A lignina é constituída por polímero complexo de estrutura amorfa, com componentes aromáticos e alifáticos, que se associa a celulose e hemicelulose durante a formação da parede celular dos vegetais e tem como finalidade conferir rigidez a mesma. Sua concentração nas fibras influencia a estrutura, as propriedades, a morfologia, a flexibilidade e a taxa de hidrólise (Brauss, 1952; Passos, 2005).

De acordo com a sua origem as fibras vegetais podem ser agrupadas em fibras de semente (ex.algodão), raiz (ex. zacatão), caule (ex. linho, juta, cânhamo), folhas (ex. bananeira, piaçava, sisal) e fruto do coco (Morassi, 1994). Segundo Aragão et al (2005), a fibra do coco verde (frutos de 07 a 08 meses de idade) é classificada como fibra branca longa e os valores médios de suas principais propriedades físico-químicas são apresentados no Quadro 1. 
Quadro 1. Valores médios das principais propriedades da fibra de coco verde

\begin{tabular}{|c|c|}
\hline PROPRIEDADES & VALORES \\
\hline $\mathrm{pH}$ & 5,4 \\
\hline Condutividade elétrica & $1,8 \mathrm{dS} / \mathrm{m}$ \\
\hline Relação C/N & 132 \\
\hline Densidade & $70 \mathrm{~g} / \mathrm{L}$ \\
\hline Porosidade total & $95,6 \%$ \\
\hline Retenção de água & $538 \mathrm{~mL} / \mathrm{L}$ \\
\hline Água facilmente assimilável & $19,8 \%$ \\
\hline Percentagem de lignina & $35 \mathrm{a} 45 \%$ \\
\hline Percentagem de celulose & 23 a $43 \%$ \\
\hline Percentagem de hemicelulose & 3 a $12 \%$ \\
\hline
\end{tabular}

Fonte: Adaptado pelos autores de Aragão et al (2006).

No Quadro 2 são apresentados dados da composição química de algumas fibras vegetais, oriundas de cultivo principal e de subprodutos da agricultura.

Quadro 2. Composição química de algumas fibras vegetais (\% em peso).

\begin{tabular}{|c|c|c|c|}
\hline Fibra & Celulose & Hemicelulose & Lignina \\
\hline Algodão & 82,7 & 5,7 & - \\
\hline Juta & 64,4 & 12,0 & 11,8 \\
\hline Linho & 64,1 & 16,7 & 2,0 \\
\hline Rami & 68,6 & 13,1 & 0,6 \\
\hline Sisal & 65,8 & 12,0 & 9,9 \\
\hline Bagaço de cana & $32-48$ & $19-24$ & $23-32$ \\
\hline Folha de abacaxi & $70-82$ & 18,0 & $5-10$ \\
\hline Folha de bananeira & $60-65$ & $6-8$ & $5-10$ \\
\hline
\end{tabular}

Fonte: Adaptado de Passos (2005) e Silva (2003).

Como observado nos quadros acima, as fibras de casca de coco têm percentual menor de celulose em comparação as outras fibras vegetais, porém a quantidade de lignina é em torno de duas a quatro vezes maior do que os valores para a juta e o sisal, oferecendo-lhe um comportamento diferenciado com relação as outras fibras. O Quadro 3 apresenta as propriedades físicas de algumas fibras vegetais e sintéticas normalmente usadas como reforço em compósitos. 
Quadro 3 - Propriedades físicas de algumas fibras vegetais e sintéticas.

\begin{tabular}{|c|c|c|c|c|c|}
\hline Fibra & Diâmetro $(\boldsymbol{\mu m})$ & $\begin{array}{c}\text { Densidade } \\
\left(\mathbf{g} / \mathbf{c m}^{\mathbf{3}}\right)\end{array}$ & $\begin{array}{c}\text { Resistência à } \\
\text { tração } \\
(\mathbf{M P a})\end{array}$ & $\begin{array}{c}\text { Módulo de } \\
\text { Elasticidade } \\
\text { (GPa) }\end{array}$ & $\begin{array}{c}\text { Alongamento } \\
\text { (\%) }\end{array}$ \\
\hline Algodão & $16-21$ & $1,5-1,6$ & $287-597$ & $5,5-12,6$ & $7-8$ \\
\hline Juta & 200 & 1,3 & $393-773$ & 26,5 & $1,5-1,8$ \\
\hline Linho & - & 1,5 & $345-1035$ & 27,6 & $2,7-3,2$ \\
\hline Cânhamo & - & - & 690 & - & 1,6 \\
\hline Rami & - & 1,5 & $400-938$ & $61,4-128$ & $3,6-3,8$ \\
\hline Sisal & $50-300$ & 1,45 & $511-635$ & $9,4-22$ & $3-7$ \\
\hline Casca de coco & $100-450$ & $1,15-1,45$ & $131-175$ & $4-13$ & $15-40$ \\
\hline Vidro - E & $8-14$ & 2,5 & $2000-3500$ & 70 & $1,8-3,2$ \\
\hline Carbono & $7-10$ & $1,6-1,9$ & 4000 & $230-240$ & $1,4-1,8$ \\
\hline
\end{tabular}

Fonte: Silva (2003).

Visualizando o Quadro 3, pode-se observar que o maior valor de densidade é da fibra de vidro o que confere peso maior aos compósitos que utilizam esta fibra, pois quanto maior a densidade da fibra maior o peso do compósito formado com ela. Com relação à resistência a tração e ao módulo de elasticidade, as fibras sintéticas tem valores maiores do que às fibras vegetais, sendo as fibras de casca de coco as que apresentam os menores valores. Os valores de alongamento são semelhantes tanto nas fibras sintéticas como vegetais; exceto para as fibras de algodão e principalmente de cascas de coco que possuem valores bem mais altos.

Por meio dos Quadros 1 e 3, conclui-se que as fibras de casca de coco têm valores de celulose mediana e lignina alta comparada com as outras fibras vegetais. Com relação as propriedades mecânicas, alongamento, resistência a tração e módulo de elasticidade, se faz necessário uma análise mais detalhada sobre as características da fibra como: idade; tipo de celulose; relação entre celulose, hemicelulose e lignina, dentre outras para determinar a sua utilização em compósitos (Passos, 2005). Na Figura 1 apresenta-se uma imagem da fibra do coco.

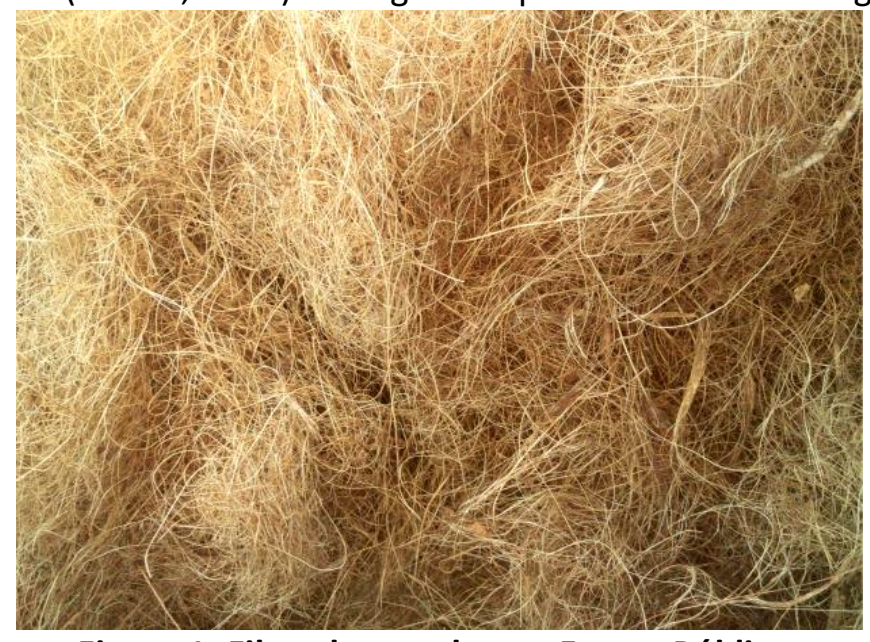

Figura 1: Fibra de coco bruta. Fonte: Pública.

Outra vertente de aplicação da fibra de coco é associada com muitas inovações tecnológicas têm surgido na área da nanotecnologia, sendo uma delas os nanocristais de celulose. 
Esses cristais são extraídos a partir de fibras vegetais lignocelulósicas, que são considerados compósitos de fibrilas de celulose, agregadas pela lignina e hemicelulose. O processo de extração de nanocristais consiste no isolamento dessas fibrilas de celulose, ou seja, na remoção dos compostos agregadores (Silva et al., 2009).

Os nanocristais de celulose podem ser obtidos a partir de fibras lignocelulósicas, como a proveniente do bagaço da cana-de-açúcar, da casca do arroz, da pluma do algodão e da casca do coco verde (Teixeira et al., 2010; Rosa et al., 2010). Nanocristais de celulose têm como grande vantagem a matéria-prima, que é proveniente de fontes renováveis, biodegradáveis e abundantes em países em desenvolvimento, como o Brasil.

Nanocristais de celulose podem ser aplicados em áreas como indústrias automobilísticas e na química de polímeros e compósitos. Estes nanocristais têm um grande potencial como agente de reforço em compósitos, podendo ser usados em plásticos sintéticos e em biopolímeros, melhorando a biodegradabilidade de plásticos, assim como melhorando as propriedades mecânicas dos novos materiais (Silva et al., 2009).

A obtenção de nanocristais de celulose ocorre com a realização das seguintes etapas: moagem, lavagem, clareamento, hidrólise ácida e diálise. Dependendo do tipo de fibra, algumas dessas etapas não são necessárias e diferentes quantidades de insumos são utilizadas. Ambas as fibras requerem a moagem, hidrólise ácida e diálise, mas as etapas de lavagem e clareamento são necessárias apenas à fibra de coco verde. Esses processos foram definidos por Rosa et al. (2010) para a extração a partir da fibra de coco verde e por Teixeira et al. (2010) para a extração a partir da fibra de algodão. Logo, inúmeras alternativas podem ser direcionadas a aplicação desse subproduto.

O objetivo este trabalho, então, foi analisar as estratégias para o aproveitamento de resíduos de casca de coco, visando à redução de impactos ambientais. Bem como, a verificação do tipo e do nível de benefícios econômicos e sociais através da tecnologia com a geração de trabalho e renda e beneficiamento de casca de coco verde para fabricação e comercialização solidária de produtos artesanais e insumos agrícolas e industriais, por meio de estudos que já comprovaram que as cascas de coco podem ser aproveitadas para diversos fins.

\section{MATERIAIS E MÉTODOS}

Trata-se de um estudo bibliográfico com abordagem qualitativa de cunho descritivo exploratório e levantamento de dados em agroindustriais e principais áreas de geração de resíduos do coco.

A busca de dados deu-se nas bases eletrônicas da Biblioteca Virtual (BV) e Scientific Eletronic Library Online (SciELO Brasil) com as palavras-chave nas respectivas bases: coco, resíduos, sustentabilidade e meio ambiente. Na base do SciELO recorreu-se ao operador lógico and para combinação das palavras no rastreamento das produções científicas.

Foram definidos os seguintes critérios de inclusão: a) artigos publicados na íntegra no período de janeiro de 1999 a maio de 2012; b) correlação dos indexadores envolvidos; c) temática de forma clara no título. Excluíram-se os artigos repetidos e os que tinham disponível nas bases eletrônicas apenas os resumos, perfazendo o corpus documental deste estudo 24 artigos científicos.

De uma forma descritiva foram desenvolvidos os mecanismos adotados pelas 
agroindústrias no estado do Rio Grande do Norte, e sua importância no contexto sócioeconomico-ambiental, em especial, com destaque para as principais medidas mitigadoras adotadas.

A análise dos dados foi feita segundo a análise de conteúdo descrita por Bardin (1979), que diz respeito a um conjunto de técnicas de análise que visa obter por procedimentos sistemáticos e objetivos o conteúdo das mensagens e indicadores que permitam a inferência de conhecimentos. Em especial, utilizou-se a análise temática que segundo Minayo (2010) comporta um feixe de relações e podem ser graficamente apresentada através de palavras, frases ou resumos. Seguiramse três etapas: pré-análise, exploração do material e tratamento dos resultados obtidos e interpretação.

Dessa forma, os dados foram apresentados em relação ao perfil do corpus documental em estudo, à qualidade metodológica das produções científicas, dados produtivos, os fatores interferentes nas questões técnicas e aspectos determinantes.

\section{CENÁRIO DA PRODUÇÃO DO COCO}

Na última década, o cultivo mundial do coqueiro registrou acréscimo na produção sem alteração substancial de área de plantio e também de colheita. De acordo com a FAO (2011), em 1998, a produção mundial foi ao redor de 49 milhões de toneladas, numa área colhida de 11,2 milhões de hectares, enquanto que, no ano de 2008 a produção foi aproximadamente de 60,7 milhões de toneladas em uma área colhida ao redor de 11,2 milhões de ha, representando um incremento de produtividade em termos globais. Cerca de $80 \%$ da área plantada com coqueiro situa-se na Ásia (Índia, Filipinas, Indonésia, Sri Lanka e Tailândia) e o restante distribuída entre África, América Latina, Oceania e Caribe (Fontes; Wanderley, 2010). A Indonésia é destacada como o maior produtor mundial de coco, seguido por Filipinas e Índia, entretanto, em área colhida, a Filipinas destaca-se com uma maior área cultivada (Quadro 4).

Quadro 4: Produção (t) e área colhida (ha) mundial e dos principais países produtores de coco, em 2011.

\begin{tabular}{|c|c|c|}
\hline País & Produção (t) & Área Colhida (ha) \\
\hline Indonésia & 19.500 .000 & 2.950 .000 \\
\hline Filipinas & 15.319 .500 & 3.379 .740 \\
\hline Índia & 10.894 .000 & 1.940 .000 \\
\hline Brasil & 2.759 .044 & 287.016 \\
\hline Mundo & 60.713 .136 & 11.230 .626 \\
\hline
\end{tabular}

Fonte: FAO, 2011.

O Brasil é líder mundial na produção de coco verde, com uma área equivalente a 57 mil hectares plantados. Em 2007, cerca de 2,77 bilhões de toneladas de cocos foram produzidas, em uma área cultivada de 273.459 hectares (FAO, 2011). O aumento na produção e no consumo de água de coco tem gerado cerca de 6,7 milhões de toneladas de casca/ano, acarretando um sério problema ambiental, sobretudo para as grandes cidades, dado cerca de $80 \%$ a $85 \%$ do peso bruto do coco verde é considerado lixo (Machado; Damm; Junior, 2009). 
No entanto, cerca de $80 \%$ a $85 \%$ do peso bruto do coco verde representam lixo (cascas). 0 destino deste lixo são os lixões que crescem assustadoramente, principalmente nos grandes centros urbanos do país. (Rosa et al, 2001).

A decomposição da casca de coco leva por volta de dez anos e os custos com transporte e disposição desses resíduos não são nada baratos para o serviço de limpeza urbana. Além disso, o descarte desse resíduo sólido representa um custo adicional visto que as indústrias processadoras são incluídas nos chamados "grandes geradores de lixo" cabendo-lhes a responsabilidade pela coleta do material residual (op. cit.). Cada copo com $250 \mathrm{ml}$ de água de coco, que despreocupadamente se bebe na praia, gera aproximadamente um quilo de lixo, principalmente nas regiões litorâneas do país que vivem do turismo regional, onde o consumo do coco é intenso tanto por turistas quanto pelos nativos (Senhoras, 2003). Não há dúvidas que grandes consequências são geradas para o meio ambiente.

O estudo do potencial de aproveitamento tecnológico dos resíduos provenientes do coco verde pode ser uma alternativa para diminuir o espaço ocupado por estes resíduos em aterros sanitários e lixões (Moura, 1999).

Devido à geração de resíduo o aproveitamento das cascas de coco vem sendo feito em alguns estados brasileiros a exemplo do Pará, Ceará e Rio de Janeiro. Empresas automobilísticas, de beneficiamento do coco, a Empresa Brasileira de Pesquisas Agropecuárias - EMBRAPA, Universidades Federais e Estaduais, dentre outras, estão investindo em pesquisas para encontrar maneiras de utilização das cascas de coco verde (Moura, 1999).

Devido à grande produção de água de coco nas agroindústrias, houve a necessidade de descobrir o que fazer com todo o resíduo proveniente da casca do coco verde. Atualmente, alguns estudos estão sendo conduzidos para verificar a potencialidade desse material, principalmente, como substrato orgânico ou cobertura morta para cultivos agrícolas. Há algumas indicações também do uso desta matéria-prima para fabricação de carvão ativado ou incorporação na formulação de elastômeros, aumentando a sua resistência mecânica. A água de coco verde é uma bebida refrescante, agradável e bastante consumida, não somente por suas qualidades sensoriais, mas também pelas suas funções nutricionais e terapêuticas. Por apresentar uma composição rica em açúcares e sais.

Existem hoje no Brasil empresas que atuam na reciclagem de coco verde e que busca agregar valor desenvolvendo produtos sustentáveis, e ao atuar no reaproveitamento de resíduos sólidos. O aproveitamento de resíduos sólidos originados dos diferentes processos industriais vem recebendo mais atenção nos últimos anos, sendo que esses resíduos envolvem significativas quantidades de materiais, que são fontes de matéria-prima orgânica e que podem ser reaproveitados e utilizados na fabricação de outros produtos (Jerônimo, 2012).

Existe uma preocupação mundial com o conceito de sustentabilidade e é preciso fortalecer ações ambiental e socialmente corretas, mas que sejam economicamente viáveis (Neves; Castro, 2007).

\section{ALTERNATIVAS ANALISADAS}

O desenvolvimento de alternativas de aproveitamento da casca de coco verde possibilita a redução da disposição desses resíduos sólidos em áreas inadequadas e proporciona uma nova 
opção de rendimento junto às indústrias de produção e à sociedade, uma vez que poderá ser fonte geradora de renda e empregos, criando postos de trabalho e oportunidades de uma vida melhor para todos, existe empresas do estado do Rio Grande do Norte, utilizam a quenga do coco para abastecer as caldeiras e suas cinzas para adubação dos coqueiros.

Examinando-se dados sobre a utilização racional do coco, pode-se observar a existência de várias empresas nacionais e internacionais que já aproveitam a casca do coco para funções que vão desde a simples queima como combustível, em substituição a lenha, até a concretagem, passando pelo carvão ativado, xaxim, fertilização do solo, isolamento térmico e acústico, estofamento de bancos e poltronas para veículos automotores e até artesanatos de fibra da casca de coco (Silva et.al., 2003). Assim, a fibra do coco verde pode ser usada na confecção de diversos produtos de utilidade para a agricultura, indústria e construção civil, em substituição a outras fibras naturais e sintéticas.

Em seu estudo, Senhoras (2003) apresentaram as variadas formas de aplicação da casca do coco, que até recentemente seguiam para o lixo, alertando para as suas características, necessariamente multidimensionais. E relatou sobre a lei cinqüentenária $\mathrm{n}$ - 594 , de 24 de dezembro de 1948, ainda em vigor, que dispõe sobre diversos benefícios fiscais e econômicos para empresas exploradoras de fibras de coco verde com o aproveitamento da matéria prima nacional.

\section{Utilização do coco verde na produção de mantas e telas para proteção do solo}

A fibra do coco, verde ou maduro, pode ser empregada na área agrícola como matériaprima para a proteção de solos, no controle da erosão e na recuperação de áreas degradadas. A fibra, tecida em forma de manta é um excelente material para ser usado em superfícies sujeitas à erosão provocada pela ação de chuvas ou ventos, como em taludes nas margens de rodovias e ferrovias, em áreas de reflorestamento, em parques urbanos e em qualquer área de declive acentuado ou de ressecamento rápido (Aragão, 2002).

No estudo realizado por Gomes (2005) utilizando a bioengenharia como ferramenta para restauração ambiental das margens do rio São Francisco, através do uso do biotêxtil fabricado com $100 \%$ de fibra de coco, verificou-se que as mantas e telas utilizadas na bem sucedida recuperação de áreas degradadas têm lenta decomposição, protegem o solo diminuindo a evaporação aumentando a retenção de umidade, protegendo e aumentando a atividade microbiana do solo e, consequentemente, criando as condições favoráveis ao desenvolvimento vegetal.

Ainda segundo Senhoras (2003) e Jerônimo (2012) existem ainda redes orgânicas tecidas com fibra de coco verde, em cujas malhas são feito o plantio da espécie vegetal desejada. Dessa forma, as mantas podem trazer as sementes de gramíneas incorporadas às fibras, as quais germinarão tão logo sejam fixadas no solo e regadas regularmente. Na Figura 1 é apresentado um exemplo desse tipo de reaproveitamento. 


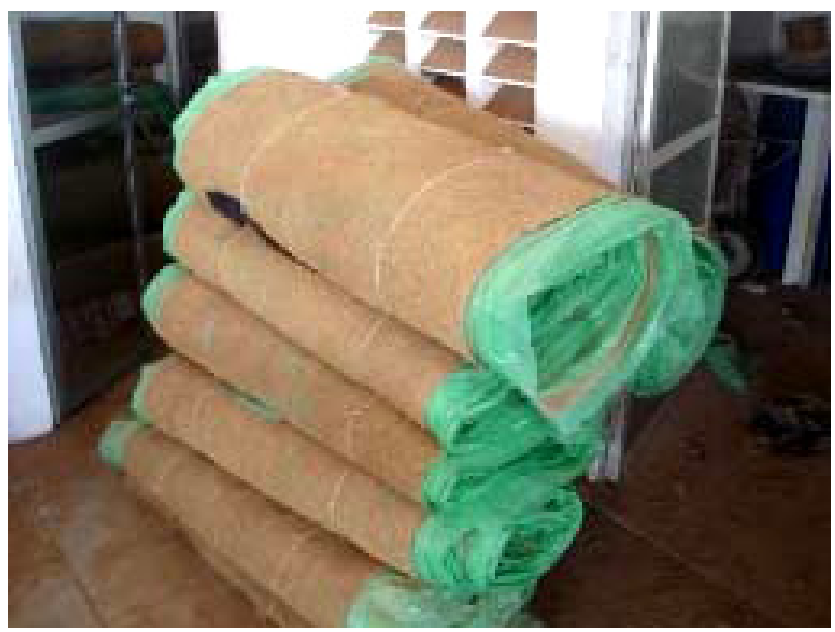

Figura 2: Mantas de fibra de coco. Fonte: EMBRAPA.

O sistema de telas e mantas biodegradáveis tem a vantagem de proporcionar a rápida recuperação do solo e a um baixo custo, se comparado com outros sistemas. Tem ainda a vantagem de ser incorporado ao terreno com o passar do tempo, diminuindo o impacto gerado sobre o meio ambiente. Podem-se salientar também os ganhos estéticos para a paisagem logo após a instalação dos mesmos (Jerônimo, 2012).

\section{Utilização do coco na geração de energia térmica.}

A maior parte das fábricas de cerâmicas utiliza a madeira como energia para os seus fornos, contribuindo para o desmatamento de arbustos. Uma boa alternativa é a utilização da casca de coco para servir de combustível para esses fornos. Na indústria convencional do coco maduro, a casca de coco é largamente utilizada como combustível para as caldeiras. Já no caso do fruto imaturo, o alto teor de umidade presente na casca (85\%) dificulta seu aproveitamento direto, exigindo uma etapa prévia de secagem que somente é considerada economicamente viável para produtos de alto valor agregado (Silva et al, 2003).

\section{Utilização do coco no isolamento acústico.}

A fibra de coco pertence à família das fibras duras e tem como principais componentes a celulose e o lenho que fazem com que ela tenha índices elevados de dureza e rigidez, transformando-a em um material quase perfeito para o isolamento acústico e térmico, conforme Figura 2. A fibra de coco verde e maduro contribui para uma redução substancial dos níveis sonoros, quer de impacto, quer aéreos, sendo a solução ideal para muitos dos problemas na área acústica, superando largamente os resultados obtidos com a utilização de outros materiais. Existindo empresas de renome nacional, como a Amorim Isolamentos que já tem produtos com essa finalidade e sendo algo a melhorar os desempenhos econômicos da industrialização do coco, 
conforme descrevem Jerônimo; Coelho (2012).

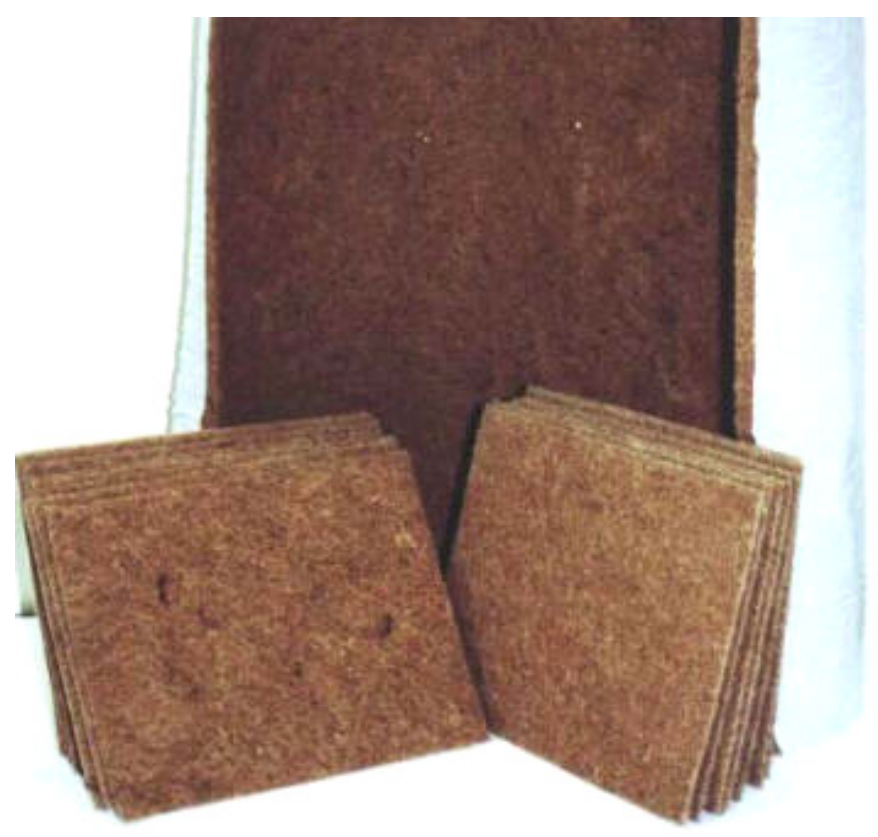

Figura 2. Manta Anti-ruído. Fonte: D’arte flores (2007).

\section{Utilização da fibra do coco na indústria automobilística.}

A fibra de coco é utilizada na fabricação de peças como encostos de cabeça, párasol interno, assentos e encostos de bancos, que equipam os veículos da marca Mercedes-Benz produzidos no Brasil. A utilização dessa fibra natural nos veículos foi possível graças a uma iniciativa ligada à pobreza e o meio ambiente na Amazônia (Poema), que está unindo pequenos produtores de coco no Interior do Pará à multinacional Alemã DailerCrysler, a Universidade Federal do Pará e a Unicef. Desenvolvido desde 1992, em Belém, no Pará, o projeto atingiu simultaneamente os propósitos de conter a devastação dos ecossistemas amazônicos, fixar e dar trabalho à população local e promover a utilização de matérias-primas renováveis (Embrapa, 2010).

\section{Utilização de tijolos de terra crua estabilizados com fibra de coco verde.}

Os tijolos de adobe produzidos com fibra de coco verde trazem um beneficio ambiental inquestionável, tanto pela redução da quantidade de terra extraída por ser substituída pela fibra quanto pela redução de resíduos nos aterros sanitários, sendo dada uma destinação econômica a um resíduo considerado como lixo (Soares et al., 2008).

$\mathrm{Na}$ avaliação dos tijolos de adobe produzidos com fibras de coco como alternativa ambiental considera-se que os mesmos são viáveis. Pois, na avaliação dos aspectos ambientais de sua produção, verifica-se que a extração de terra e o gasto energético apresentam, respectivamente, os seguintes atributos: otimização da utilização da matéria-prima, pois a terra 
pode ser reutilizada inúmeras vezes, eficiência no encapsulamento de um resíduo agroindustrial de difícil degradação, e valor nulo de gasto energético, sendo ainda um material alternativo na luta contra o aquecimento global, pois para a sua fabricação não é necessária a utilização de combustíveis fósseis como o carvão mineral, dentre outros. Na produção do adobe com a fibra de coco não há emissões de poluentes na atmosfera, bem como a não existência de emissões de resíduos sólidos nem líquidos.

Segundo Soares et al (2008) apesar do custo dos tijolos de adobe produzidos com fibras de coco verde ser superior aos tijolos de adobe sem a presença das fibras, aquele têm características físicas e ambientais muito mais desejáveis diante do tijolo sem a presença de fibras, além de haver a possibilidade de redução deste valor, caso aplique-se a lei citada por Senhoras (2003) relacionada aos diversos benefícios fiscais concedidos a empresas que se instalarem para a exploração da fibra de coco verde. Isto sem mencionar os benefícios ambientais.

\section{Utilização da fibra de coco como substrato}

Segundo Oliveira et. al. (2008), o cultivo de plantas em substratos alternativos tem sido cada vez mais empregado em nosso país. Os substratos devem ter baixo custo, ser disponíveis nas proximidades da região de consumo, apresentar suficiente teor de nutrientes, permitirem aeração e retenção de umidade, bem como, favorecer a atividade fisiológica das raízes. Na opção por um determinado material como substrato, objetiva se otimizar as condições para o desenvolvimento da planta.

Desse modo, a casca de coco, segundo Rosa et. al (2001), é constituída por: uma fração de fibras e outra fração denominada pó, que se apresenta agregada às outras fibras. $O$ pó da casca de coco é o material residual do processamento da casca de coco maduro para obtenção da fibra longa. Atualmente, o resíduo ou pó da casca de coco maduro tem sido indicado como substrato agrícola, principalmente por apresentar uma estrutura física vantajosa,proporcionando alta porosidade, alto potencial de retenção de umidade, por ser biodegradável, não poluente e estimulador do enraizamento .

De acordo com Carrijo et al. (2002) o pó e a fibra do coco verde apresentam características como facilidade de produção, alta disponibilidade, longa durabilidade sem alteração de suas características físicas, possibilidade de esterilização e abundância da matéria prima, que é renovável e de baixo custo. A crescente utilização de compostos orgânicos como substrato reflete a necessidade de práticas agrícolas sustentáveis que minimizem o impacto ambiental. Logo, o pó da casca de coco verde surge como uma alternativa que evita a aplicação de substratos que produzem impactos ambientais negativos - turfas, areia, entre outros.

\section{Utilização da fibra de coco na produção de papel.}

O consumo de papel derivado da indústria madeireira é uma das causas de desflorestamento no mundo, o que ilustra a preocupação de encontrar alternativas não madeireiras, tal qual o retorno de resíduos agrícolas como fonte primária para a fabricação de papel. Estima-se que os países em desenvolvimento têm um papel fundamental neste processo, pois neles se encontram disponíveis uma cifra de 2.500 milhões de toneladas de resíduos da 
produção agrícola e agroindustrial (Senhoras, 2003).

O consumo de papel derivado da indústria madeireira é uma das causas de desflorestamento no mundo, o que ilustra a preocupação de encontrar alternativas não madeireiras, tal qual o retorno de resíduos agrícolas como fonte primária para a fabricação de papel. Estima-se que os países em desenvolvimento têm um papel fundamental neste processo, pois neles se encontram disponíveis uma cifra de 2.500 milhões de toneladas de resíduos da produção agrícola e agroindustrial (Senhoras, 2003).

\section{Utilização da fibra de coco na engenharia civil e de materiais.}

Os compósitos reforçados com fibras naturais pode ser uma alternativa viável em relação àqueles que usam fibras sintéticas como as fibras de vidro. As fibras naturais podem conferir propriedades interessantes em materiais poliméricos, como boa rigidez dielétrica, melhor resistência ao impacto e características de isolamento térmico e acústico (Rosa et. al., 2001).

A indústria da borracha é receptora também de grande número de projetos envolvendo produtos ecológicos diversos, desde a utilização da fibra do coco maduro e verde na confecção de solados de calçados, até encostos e bancos de carros, estofamentos e colchões. Dessa forma é possível diminuir o preço do produto final, à medida que se aumenta a quantidade de utilização do resíduo do coco verde (Rosa et. al., 2001).

A fibra de coco verde também age como um componente reforçador da matriz dos polímeros. Pois, altera as propriedades mecânicas destes compostos tais como resistência em relação à tensão, tração e elongação na ruptura (Senhoras, 2003).

As fibras podem ser adicionadas às matrizes a base de cimento como reforço primário e secundário. Elas trabalham como reforço primário em produtos de pequena espessura onde as barras convencionais de reforço não podem ser utilizadas. Nessas aplicações, as fibras atuam para aumentar tanto a resistência quanto a ductilidade do compósito. Em componentes como lajes e pavimentos, as fibras são adicionadas para controlar a fissuração causada pela umidade ou variações de temperatura e, nessas aplicações, elas funcionam como reforço secundário. Elas têm sido utilizadas para produzir materiais de pequena espessura e de baixo custo, para serem utilizados em habitações populares (Toledo Filho, 1997).

\section{Utilização da fibra de coco na produção de carvão vegetal (briquete)}

O resíduo do coco também serve para a produção de briquetes, um tipo de carvão vegetal evitando assim o impacto ambiental nas matas, este tipo de carvão é muito mais resistente, além de não comprometer o meio ambiente tal prática vem sendo adotada por algumas organizações, tendo-se observado exemplos em escalas industriais no estado do Rio Grande do Norte (Jerônimo, 2012).

\section{Fabricação de vasos com fibra de coco.}

O processo de produção desses vasos tem início colocando as cascas de coco seco em uma 
batedeira de porte industrial para ser obtida a fibra, estas são enfardadas logo após. Esse fardo vai para um misturador de alta potência no qual as fibras são "penteadas" ou seja melhor separadas resultando em um manto de fibra de coco (Bittencourt, 2008).

Logo, como o xaxim é um produto ameaçado de extinção, já existem empresas, que produzem produto semelhante derivado da casca de coco, pois esses produtos são ecologicamente corretos, e também são produzidos com material renovável.

\section{CONCLUSÕES}

Conclui-se que o estudo do aproveitamento tecnológico dos resíduos do coco verde, pode ser utilizado de várias formas e atividades nobres como a adubação, o estofamento de bancos para veículos automotores e até energia térmica, sem contar com o artesanato entre outros. Porém, $\mathrm{O}$ elemento de bloqueio destas práticas é a sua economicidade, pois se torna o maior gargalo para sua aplicação.

Sob a ótica ambiental, tais medidas, em especial, conferem um grau de atratividade superior devido ao desenvolvimento de alternativas de aproveitamento da casca de coco possibilita a redução da disposição desses resíduos sólidos em áreas inadequadas, contribuindo na redução do custo do serviço de limpeza urbana, na diminuição de problemas ambientais e de saúde pública, visto que o lixo atrai uma quantidade enorme de insetos e roedores, que se proliferam e espalham doenças, além de gerar mau cheiro e, principalmente, poluir o solo e as águas superficiais e subterrâneas através do chorume, aumentando a vida útil dos aterros. Conceito esse atrelado as novas perspectivas da política nacional de resíduos sólidos brasileira.

As vantagens da utilização (considerando a junção de todas as discussões) são função de sua maior durabilidade, flexibilidade, possibilidade de ser reciclável e a biodegradabilidade. Ou seja, a potencialidade de substituição dos produtos oriundos de fontes não sustentáveis, além de ser produzidos com alta tecnologia, deve propiciar o aumento de renda para a população e conseqüentemente a redução de desemprego, além da consciência ambiental dos resíduos gerados e reciclados. Sendo assim, a alternativa de reuso desse resíduo agroindustrial torna-se de grande valia.

Por fim, são recomendados estudos de viabilidade econômica para aproveitando das potencialidades associadas ao desenvolvimento das atividades propostas, sobretudo, acompanhada de análises de mercado para ponderar tais elementos.

\section{REFERÊNCIAS BIBLIOGRÁFICAS}

AGRIANUAL 2006: anuário da agricultura brasileira. Coco-da-baía. São Paulo: FNP, Consultoria e Agroinformativos, 2006. p. 286-292.

ARAGAO, W. M. Coco: pós-colheita. Brasília: EMBRAPA, 2002. ( Série frutas do Brasil).

ARAÚJO, M. J. Fundamentos do agronegócio. 2. ed - São Paulo: Atlas, 2005.

BATALHA, M. O. Gestão Agroindustrial: Grupo de Estudos e Pesquisas agroindustriais, Vol. 1 e 2, São Paulo: Atlas, 2001. 
BENASSI, A. C. Informes sobre a produção de coco. Disponível em: <www.todafruta.com.br/toda fruta/mostra_conteudo.asp?,2006>. Acessado em 24 abr. 2012.

BENASSI, A. C. Informes sobre a produção de coco. Disponível em: <www.todafruta.com.br/portal/icNoticiaAberta.asp?idNoticia=12743>. Acessado em 24 abr. 2012.

BITENCOURT, D. V.. Potencialidades e estratégias sustentáveis para o aproveitamento de rejeitos do coco (Cocos nucifera L.). São Cristovão, Sergipe, 2008. Dissertação (Mestrado - Núcleo de Pós-Graduação em Desenvolvimento e Meio Ambiente) Universidade Federal de Sergipe, 2008.

BRAUSS. F. E. The chemistry of lignin. Academic Press INC. New York. 1952.cap3, 14-23p

CARRIJO, O. A.; LIZ, R. S.; MAKISHIMA, N. Fibra da casca de coco verde como substrato agrícola. Horticultura Brasileira, Brasília, v.20, n. 4, p. 533-535, 2002.

EMBRAPA (2010), A introdução do coqueiro no Brasil. Importância histórica e agronômica. Disponível em: www.Cpatc.embrapa.br/download/Documentos47.doc.Acessado em 24 abr. 2012.

EMBRAPA, Importância econômica da cocoicultura no Brasil. Disponível em: <www.sistemasdeproducao.cnptia.embrapa.br/FontesHTML/Coco/ACulturadoCoqueiro/importancia.htm>. Acessado em 24 abr. 2012.

FAO 2011. Disponível em: www.faostat.org.br Acesso em: 15 out. 2012.

FERREIRA, J. M. S.; WARWICK, D. R. N.; SIQUEIRA, L. a. Cultura do coqueiro no Brasil. 2ed. Aracaju: Embrapa-SPI, 1998. $309 \mathrm{p}$.

GOMES, L. G. N. A bioengenharia como ferramenta para restauração ambiental das margens do Rio São Francisco. Aracaju: UFS/NESA, 2005. (dissertação de mestrado).

GRIPPI, S. Reciclagem e sua História: guia para as prefeituras municipais. Rio de janeiro. 2001.

IBGE - Produção Agrícola Municipal 2006. Disponível em: <www.sidra.ibge.gov.br/bda/pesquisa> Acessado em 24 abr. 2012.

JERONIMO, C. E. M. Tecnologias limpas aplicadas a gestão dos resíduos do coco. Revista Qualidade Emergente, 2012, v.3 n.1: $20-29$.

JERONIMO, C. E. M.; COELHO, M. S. Sensibilidade do estudo de viabilidade técnico-econômica de uma agroindústria de processamento de coco. Revista Economia e Desenvolvimento, n. 24, vol. 1, 2012.

MORASSI, O. J. Fibras naturais - aspectos gerais e aplicação na indústria automobilística. In: Congresso Brasileiro de Engenharia e ciência dos materiais. 1994. São Paulo-SP.

MOURA, J. I. L.; REBOUÇAS, T. N. H. Coco: Produção e mercado. Vitória da Conquista, BA, DFZ/UESB, 1999.

NEVES, M. F.; CASTRO, L. T. Agronegócio, Agregação de valor e Sustentabilidade. In: XXXI Encontro da ANPAD, 2007, Rio de Janeiro. [Anais..]. Rio de janeiro:ANPAD,2007.

OLIVEIRA, C. A. A.; SANTOS, T. P. e DANIEL, L. A. Aplicação de reuso de água como medida minimizadora de efluentes industriais. In: XIX Congresso Brasileiro de Engenharia Sanitária e Ambiental, Foz do Iguaçu, PR, Anais em 'CDROM' I-119, 1997.

PASSOS, P. R. de A. Destinação sustentável de cascas de coco verde:Obtenção de telhas e chapas de partículas.2005. 186f. Tese. Universidade Federal do Rio de Janeiro.Rio de Janeiro 
ROSA, M. de F.; ABREU, F. A. P. de. Água de coco: métodos de conservação. Fortaleza: Embrapa - CNPAT / SEBRAE/CE, 2000. $40 \mathrm{p}$.

ROSA, M. F.; MEDEIROS, E. S.; MALMONGE, J. A.; GREGORSKI, K. S.; WOOD, D. F.; MATTOSO, L. H.C.; GLENN, G.; ORTS, W. J.; IMAM, S. H. Cellulose nanowhiskers from coconut husk fibers: Effect of preparation conditions on their thermal and morphological behavior. Carbohydrate Polymers, 2010, doi:10.1016/j.carbpol.2010.01.059.

SANTIAGO, BHS; PANNIRSELVAM, PV. Desenvolvimento de Projeto para Produção de Fibra de Coco com Inovação de Tecnologia Limpa e Geração de Energia. Revista Analítica (ISSN 1677-3055, Ano 3, n 15, p. 56 - 62, Fev/Mar (2005).

SENHORAS, E. Estratégia de uma Agenda para a Cadeia Agroindustrial do Coco. Campinas: ed. ESC, 2003.

SILVA, O. S. de O, COSTA, W. M, SILVA, R. M. L, VIANNA, F. M. A, LIZNANDO, C. G.. Aceitabilidade de produtos para a construção civil produzidos a base de fibra de coco na visão de especialistas do setor: Um estudo de caso para a cidade de Natal. Natal, UFRN, 2003.

SILVA, R.; HARAGUCHI, S. K.; MUNIZ, E. C.; RUBIRA, A. F. Aplicações de fibras lignocelulósicas na química de polímeros e em compósitos. Química Nova, v. 32, n. 3, 2009, pg. 661-671.

SILVA, R. V. da. Compósito de resina poliuretano derivada de óleo de mamona e fibras vegetais.2003.130f.Tese.Universidade de São Paulo. São Carlos.

SILVEIRA, M. S.. Aproveitamento das cascas de coco verde para produção de briquete em Salvador - BA. Salvador, Bahia, 2008. Dissertação (Mestrado - Gerenciamento e Tecnologias Ambientais no Processo Produtivo - Ênfase em Produção Limpa,) Escola Politécnica da Universidade Federal da Bahia, 2008

SOARES, R. N, SILVA, A. C, PINHEIRO, J, C. Tijolos de terra crua estabilizados com fibras de coco verde: alternativa para habitação de interesse social. Fortaleza, CE, 2008.

TEIXEIRA, E.M.; CORRÊA, A.C.C.; MANZOLI,A.; LEITE, F.L.; OLIVEIRA,C.R.; MATTOSO, L.H.C. Cellulose nanofibers from white and naturally colored cotton fibers. Cellulose, 2010, doi: 10.1007/s10570-010-9403-0.

TOLEDO FILHO, R. Materiais Compósitos reforçados com Fibras Naturais: Caracterização Experimental. Rio de Janeiro, 1997. Tese de doutorado submetida ao Departamento de Engenharia Civil da Pontifícia Universidade Católica do Rio de Janeiro, 1997. 